\title{
Defining the solution space to accelerate climate change adaptation
}

\section{Marjolijn Haasnoot ${ }^{1,2}$ (D) $\cdot$ Robbert Biesbroek $^{3}$ (D) $\cdot$ Judy Lawrence ${ }^{4}$ (D) $\cdot$ Veruska Muccione $^{5} \cdot$ Robert Lempert $^{6}$ (D) Bruce Glavovic ${ }^{7}$}

Received: 11 February 2020 / Accepted: 23 February 2020 / Published online: 12 March 2020

(C) The Author(s) 2020

\begin{abstract}
Decision makers need better insights about solutions to accelerate adaptation efforts. Defining the concept of solution space and revealing the forces and strategies that influence this space will enable decision makers to define pathways for adaptation action.
\end{abstract}

Keywords Climate change adaptation $\cdot$ Uncertainty $\cdot$ Pathways $\cdot$ Limits $\cdot$ Solutions

\section{Introduction}

The 2010s will be remembered as the decade during which the impacts of climate change were increasingly manifest. It was also the decade when the importance of adaptation to reduce the impacts of climate change was recognized and grew. Many examples illustrate action being taken already, but despite these efforts, a pervasive adaptation gap continues to persist (UNEP 2018). Reasons for its persistence include the lack of a sense of urgency, low political willingness to act, prevalence of short-termism, and uncertainty about the future, which can all paralyse progress on adaptation (de Coninck et al. 2018). At the same time, the past decade demonstrated many examples of adaptation being enabled and implemented, for example through technological advancements, starting collaborative, and bottom-up adaptation initiatives, by mobilizing knowledge and private finance, and by implementing lowregret measures. The solution space has therefore become

Communicated by Wolfgang Cramer

Marjolijn Haasnoot

marjolijn.haasnoot@deltares.nl

1 Utrecht University, Utrecht, the Netherlands

2 Deltares, Delft, the Netherlands

3 Wageningen University, Wageningen, the Netherlands

4 Victoria University of Wellington, Wellington, New Zealand

5 University of Zurich, Zürich, Switzerland

6 RAND Corporation, Santa Monica, CA, USA

7 Massey University, Auckland, New Zealand increasingly important to understand if, when, what, and how much adaptation is taking place now and in the future.

We argue here that better understanding of the solution space for climate change adaptation, and identifying ways to influence this space, is critical for informing policy making globally to accelerate adaptation action. For example, failure to reach an agreement during COP25 in December 2019 on climate finance for developing countries is severely limiting these countries' solution space to adapt to observed and projected impacts, even though from a biophysical or political-institutional perspective many adaptation options are available. It shows that, for adaptation to take place, all pieces of the puzzle need to come together at the same time. In many cases, this requires reshaping the available solution space. Here we define, assess, and identify ways to map and influence the solution space by building upon studies on adaptation policy and decision-making (Keskitalo and Preston 2019), thresholds, limits, and barriers to adaptation (Dow et al. 2013), policy pathways (Haasnoot et al. 2013), (mal)adaptive space (Wise et al. 2014), and Shared Socio-Economic Pathways (O’Neill et al. 2017).

\section{What is the solution space?}

We define the solution space as the space within which opportunities and constraints determine why, how, when, and who adapts to climate risks (Fig. 1). The solution space is shaped by biophysical, cultural, socio-economic, and politicalinstitutional dimensions at a given moment in time. Within these dimensions, there are 'hard' (unsurpassable) limits and 'soft' (surpassable) limits (Dow et al. 2013). We argue that 
Fig. 1 Conceptualisation of the solution space (grey area), possible shaping actions, changes and shocks (arrows), and alternative adaptation pathways in the solution space (coloured lines). A changing solution space can indicate that adaptation options and pathways become available, thus opening up the solution space (full colour), or becoming unavailable/not possible to implement and thus closing down the solution space (transparent)

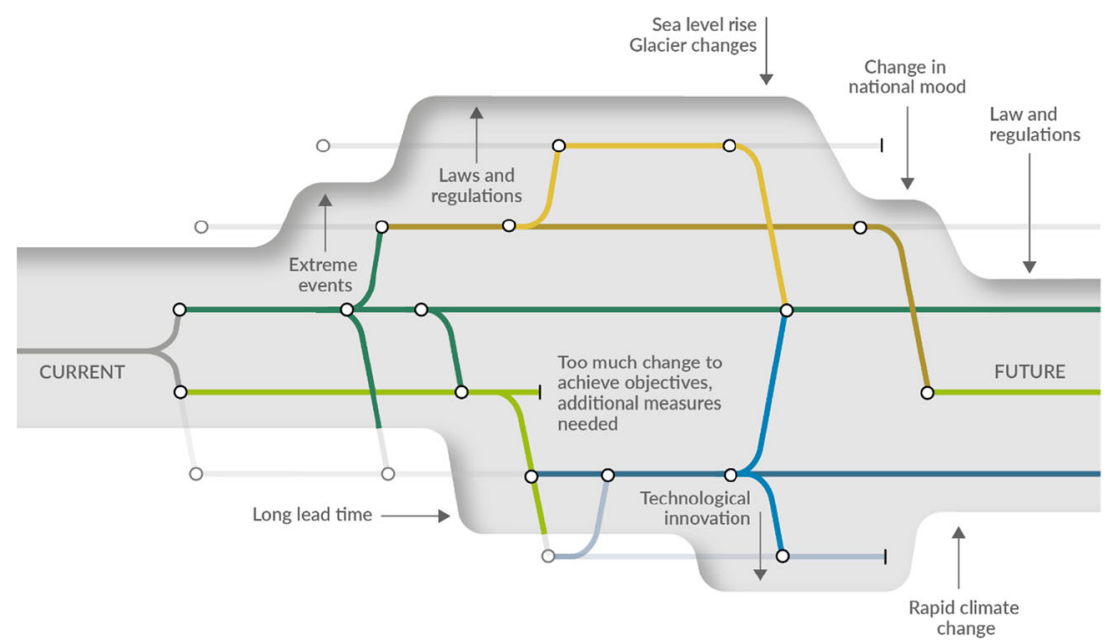

there are four key characteristics of the solution space that need to be considered to accelerate climate change adaptation.

First, the boundaries of the solution space are flexible and will change in form (e.g. how to adapt) and size (e.g. access to the number and type of solutions) over time and across contexts. The solution space can be shaped (un)intentionally by actors but is also influenced by systemic processes and forces beyond control. The solution space represents the boundaries of what adaptation is socially accepted, economically affordable, politically feasible, and technically possible and is therefore the 'room to manoeuvre'. Understanding the scope for crafting solutions is critical in the context of long-term adaptation planning and implementation (see Howlett 2019).

Second, the solution space is path dependent, in that it opens up some options and forecloses others. There is decision pathdependency arising from decisions taken now which influence future solution space, and scenario path-dependency which stems from biophysical or socio-economic changes determining the range of future available options (Haasnoot et al. 2019). The level of greenhouse gas mitigation is thus a crucial determinant of the solution space, because the rate and severity of climate change influences the need for and size of the solution space. Whereas much of the discussion on barriers and limits to adaptation assumes some level of stationarity, the notion of solution space acknowledges that time and changing conditions will play a critical role in the adaptation options available and opportunities for action. The area outside the solution space determines the residual risk, the risk that is left after adaptation (Mechler and Schinko 2016).

Third, the solution space is contested, can be applied to any administrative scale (e.g. global-local), climate impact (e.g. flood risks), actor groups (public or private), or system of concern (e.g. supply or value chains), and evolves over time. The solution space differs amongst actors, such as individual households, governments, community groups, and private organizations. In practice, the solution space is socially constructed and is contested by actors with different norms, values, and interests. A solution for one actor may construct or compound problems for another. The solution space thus is where divergent perspectives and interests can be reconciled and socially just pathways developed (NurseyBray 2017). The solution space also differs for different climate change impacts and will look different for cascading or systemic risks. For example, it is smaller when considering multiple compounding hazards and risks, and for cascading risks which have the potential to shrink the solutions space even further (Lawrence et al. 2018).

Fourth, as the shape of the solution space is in constant flux, there are opportunities for actors to influence the solution space, opening it up or closing it down. Increasing the solution space is not necessarily required for successful adaptation; the area outside the solution space is also not necessarily maladaptive, but it is simply not (yet) available.

\section{What is shaping the solution space over time?}

Changes in the solution space can take place in two ways: First, exogenous changes beyond the direct influence of the actors can expand or shrink the solution space. Second, planned actions can intentionally change the solution space for adaptation, unless hard limits occur. These changes and actions can target both the biophysical and societal dimensions, including cultural, socio-economic, and political dimensions (Table 1). In both cases, they offer a new range (i.e. larger or smaller range) of possible incremental or transformational adaptation options that become available for implementation.

Exogenous changes in the biophysical system include for example an increase in the rate of climate change impacts (top$l e f t$ ). These include slow onset or unexpected impacts such as accelerated sea-level rise, intensification of large-scale wild fires, or biodiversity losses, as well as the consequences of these impacts for humans such as casualties and damages. Such changes in turn can influence society's perspective of climate change and thus the socio-economic and political system (top-right). 
Table 1 Examples of exogenous changes and planned actions shaping the solution space. Exogenous changes in biophysical and societal systems influence the adaptation options that are effective and available to implement. Planned actions can intentionally shape the solution space and can thus be part of an adaptation plan

\begin{tabular}{|c|c|c|}
\hline & Biophysical & Societal \\
\hline $\begin{array}{l}\text { Exogenous changes that } \\
\text { influence the solutions space }\end{array}$ & $\begin{array}{l}\text { - Magnitude or rate of climate change } \\
\text { - Accelerated sea-level rise } \\
\text { - Extreme events and shocks } \\
\text { - More frequent smaller events }\end{array}$ & $\begin{array}{l}\text { - Changes in national mood or political orientation } \\
\text { - Population growth/shrink } \\
\text { - Economic growth/shrink } \\
\text { - International policies and agreement } \\
\text { - Information availability } \\
\text { - Societal up-rise and social movements }\end{array}$ \\
\hline $\begin{array}{l}\text { Planned actions to influence } \\
\text { solution space }\end{array}$ & $\begin{array}{l}\text { - Monitoring and detection of biophysical signals } \\
\text { - Technological innovations } \\
\text { - Experiments and pilots }\end{array}$ & $\begin{array}{l}\text { - Laws and regulations } \\
\text { - Awareness raising } \\
\text { - Coalitions of interests } \\
\text { - Knowledge production and fast and regular diffusion } \\
\text { - Tracking, learning, and evaluation } \\
\text { - Climate mitigation }\end{array}$ \\
\hline
\end{tabular}

Exogenous changes in the societal system can include changes in political orientation toward climate change. For instance, in New Zealand, after decades of policy shifts, increasing emissions and little adaptation, cross-party agreement delivered a Climate Change Response (Zero Carbon) Act in 2019 that provides for emission reduction targets, budgeting and planning, a national risk assessment, a national adaptation plan, and independent monitoring of emissions reduction and adaptation action, thus making strong institutional links between mitigation and adaptation, a key enabler for opening up the solutions space.

Planned actions in biophysical systems can include targeted technological innovations such as genetic modification of seeds to create salt tolerant crops and experiments that test the effectiveness of adaptation options for upscaling.

Planned actions in the socio-economic system may include innovative legislation, land use changes, and funding schemes to compensate for adaptation decisions. Other examples include awareness raising of societal actors of the need for more stringent climate actions and involving the private sector in tackling climate change impacts. Climate mitigation policies have the potential to slow down the rate of climate change if the political economy allows, which can open up the solution space, creating more time to implement adaptation actions and for ecosystems to adjust to the climate changes. However, there will be irreversible and existential impacts that do not fall into the solution space as we know it now, thus necessitating transformational adaptation, and in some cases accepting residual risk.

The boundary between exogenous and planned changes is contextual and often uncertain. For instance, local planners may succeed in influencing their nation's political orientation toward climate change or, conversely, find themselves unable to influence necessary legislative change.

The four quadrants of Table 1 shed light on key dimensions of the solution space. For example, if sea-level rise accelerates, some adaptation options are ruled out because of the required lead time for planning and implementation, or options may not be preferred due to their limited lifespan (top-left). Given large uncertainties, flexibility is required to avoid under- or over-investment, but this is difficult for decisions about rigid infrastructure, requiring technological innovations and pilots for flexible design and implementation (bottom-left) (Oppenheimer et al. 2019).

Monitoring of $\mathrm{CO}_{2}$ emissions, e.g. global warming and related sea-level rise, can help to detect early warning signals to open up the solution space in a timely manner (e.g. starting experiments to allow for nature-based solutions on a large scale) and to accelerate adaptation (bottom-left). In low-lying coastal zones, defences may need to be reinforced or people relocated, which requires space that may be (un)available or may become (un)available due to population changes (top-right). Anticipatory spatial planning combined with early warning signals could enable future dike raising or planned retreat (bottomright). Planned actions to define and translate potential solution space into lived reality, in the face of exogenous change, enables engagement with the complexity, path-dependency, uncertainty, dynamism, and contestation characterizing adaptation.

\section{How to map and mobilize the solution space?}

Understanding the solution space requires assessment of the possible evolution of boundaries, the range of adaptation options within this space, and the many governance actors and their interactions over time. Various methods exist to assess these boundaries, including models to assess the resilience of systems and performance of adaptation options, observations of biophysical or socio-economic system changes and thresholds, or labexperiments (e.g. Hinkel et al. 2018), and decision analysis approaches, to evaluate solutions in terms of effectiveness, costs, 
and co-benefits (Oppenheimer et al. 2019). Serious games can be used as tools to identify possible conflicting interests and points of agreement between different actors (Rumore et al. 2016). Exploring costs and benefits over multiple future scenarios can help to identify under which conditions the benefit of taking action outweighs socio-economic costs, thereby highlighting new opportunities for solutions. Moreover, tools can be used to integrate biophysical and socio-economic dimensions of the solution space, defining its context and local boundaries (top-row Table 1), including shared socio-economic pathways (O’Neill et al. 2017).

Adaptation pathways offer ways to map adaptation options and their path-dependency within and outside the solution space, as well as the conditions under which the options have efficacy (Haasnoot et al. 2013). This enables policy makers to identify which planned actions can be taken and in what sequence to shape the solution pace (bottom-row, Table 1). Mobilizing the concept of solution space into practice is dependent on institutional innovations to overcome the adaptation impasse that stems from climate change complexity, uncertainty, dynamism, and contestation, compounded by the path dependencies constructed by the prevailing political economy.

\section{Ways forward}

Opening up the solution space creates new possibilities to accelerate adaptation practice. First, the solution space provides a perspective to act; it provides a framing device to understand what adaptation can be done now, and in the future, and can provide insights on the available options in the short-term and those that can become available in the medium- to long-term. Second, the concept of solution space can help efforts to craft solutions over time and find levers for action to intentionally modify this space. Third, understanding the solution space is critical to assess the feasibility and effectiveness of adaptation options (de Coninck et al. 2018). Finally, better understanding the solution space could support accountability of adaptation practices worldwide.

In doing so, the solution space can help to put pieces of the adaptation puzzle together and further integrate different strands of natural and social science literature; work on projected climate change impacts and adaptation options and projections of changes in social-political-institutional systems have remained fragmented too long. Bringing these strands together is critical to better understand the room for policy and practice actions that can accelerate climate change adaptation and reduce the adaptation gap.

Open Access This article is licensed under a Creative Commons Attribution 4.0 International License, which permits use, sharing, adaptation, distribution and reproduction in any medium or format, as long as you give appropriate credit to the original author(s) and the source, provide a link to the Creative Commons licence, and indicate if changes were made. The images or other third party material in this article are included in the article's Creative Commons licence, unless indicated otherwise in a credit line to the material. If material is not included in the article's Creative Commons licence and your intended use is not permitted by statutory regulation or exceeds the permitted use, you will need to obtain permission directly from the copyright holder. To view a copy of this licence, visit http://creativecommons.org/licenses/by/4.0/.

\section{References}

de Coninck H, Revi A, Babiker M, Bertoldi P, Buckeridge M, Cartwright A, Dong W, Ford J, Fuss S, Hourcade J-C, Ley D, Mechler R, Newman P, Revokatova A, Schultz S, Steg L, and Sugiyama T (2018) Strengthening and implementing the global response. In: Global Warming of $1.5^{\circ} \mathrm{C}$. An IPCC Special Report on the impacts of global warming of $1.5^{\circ} \mathrm{C}$ above pre-industrial levels and related global greenhouse gas emission pathways, in the context of strengthening the global response to the threat of climate change, sustainable development, and efforts to eradicate poverty [Masson-Delmotte V, Zhai P, Pörtner H-O, D. Roberts, J. Skea, Shukla PR, Pirani A, Moufouma-Okia W, Péan C, Pidcock R, Connors S, Matthews JBR, Chen Y, Zhou X, Gomis MI, Lonnoy E, Maycock T, Tignor $\mathrm{M}$, and Waterfield T (eds.)]. In Press.

Dow K, Berkhout F, Preston BL, Klein RTJ, Midgley G, Shawet MR (2013) Limits to adaptation. Nat Clim Chang 3:305-307. https://doi. org/10.1038/nclimate1847

Haasnoot M, Kwakkel JH, Walker WE, ter Maat J (2013) Dynamic adaptive policy pathways: a method for crafting robust decisions for a deeply uncertain world. Glob Environ Chang 23:485-498. https:// doi.org/10.1016/j.gloenvcha.2012.12.006

Haasnoot M, van Aalst M, Rozenberg J, Dominique K, Matthews J, Bouwer LM, Kind J, Poff NLR (2019) Investments under non-stationarity: economic evaluation of adaptation pathways. Clim Change. https://doi.org/10.1007/s10584-019-02409-6

Hinkel J, Aerts JCJH, Brown S, Jiménez JA, Lincke D, Nicholls RJ, Scussolini P, Sanchez-Arcilla A, Vafeidis A, Addo KA (2018) The ability of societies to adapt to twenty-first-century sea-level rise. Nat Clim Chang 8:570-578. https://doi.org/10.1038/s41558-018-0176$\mathrm{z}$

Howlett M (2019) Procedural policy tools and the temporal dimensions of policy design. Int Rev Public Policy 1:27-45. https://doi.org/10. 4000/irpp.310

Keskitalo ECH, Preston BL (2019) Research handbook on climate change adaptation policy. Edward Elgar publishing, Cheltenham

Lawrence J, Blackett P, Cradock-Henry N, Nistor BJ (2018) Climate change: the cascade effect. Cascading impacts and implications for Aotearoa New Zealand. Wellington: Deep South Challenge 
Mechler R, Schinko T (2016) Identifying the policy space for climate loss and damage. Science. 354(80):290 LP-290292. https://doi.org/10. 1126/science.aag2514

Nursey-Bray M (2017) Towards socially just adaptive climate governance: the transformative potential of conflict. Local Environ 22: 156-171. https://doi.org/10.1080/13549839.2016.1181618

O’Neill BC, Kriegler E, Ebi KL, Kemp-Benedict E, Riahi K, Rothman DS, van Ruijven BJ, van Vuuren DP, Birkmann J, Kok K, Levy M, Solecki W (2017) The roads ahead: narratives for shared socioeconomic pathways describing world futures in the 21st century. Glob Environ Chang 42:169-180. https://doi.org/10.1016/j.gloenvcha. 2015.01.004

Oppenheimer M, Glavovic B, Hinkel J, van de Wal R, Magnan AK, AbdElgawad A, Cai R, Cifuentes-Jara M, DeConto RM, Ghosh T, Hay J, Isla F, Marzeion B, Meyssignac B, Sebesvari Z (2019) Sea level rise and implications for low-lying islands, coasts and communities. In: Pörtner HO, Roberts DC, Masson-Delmotte V, Zhai P, Tignor M,
Poloczanska E, Mintenbeck K, Alegría A, Nicolai M, Okem A, Petzold J, Rama B, Weyer NM (eds) IPCC Special report on the ocean and cryosphere in a changing climate. https://www.ipcc.ch/ site/assets/uploads/sites/3/2019/11/08_SROCC_Ch04_FINAL.pdf

Rumore D, Schenk T, Susskind L (2016) Role-play simulations for climate change adaptation education and engagement. Nat Clim Chang 6:745-750. https://doi.org/10.1038/nclimate3084

UNEP (2018) The adaptation gap report 2018. Nairobi, Kenya

Wise RM, Fazey I, Smith MS, Park SE, Eakin HC, Archer Van Garderen ERM, Campbell B (2014) Reconceptualising adaptation to climate change as part of pathways of change and response. Glob Environ Chang 28:325-336. https://doi.org/10.1016/j.gloenvcha.2013.12. 002

Publisher's note Springer Nature remains neutral with regard to jurisdictional claims in published maps and institutional affiliations. 